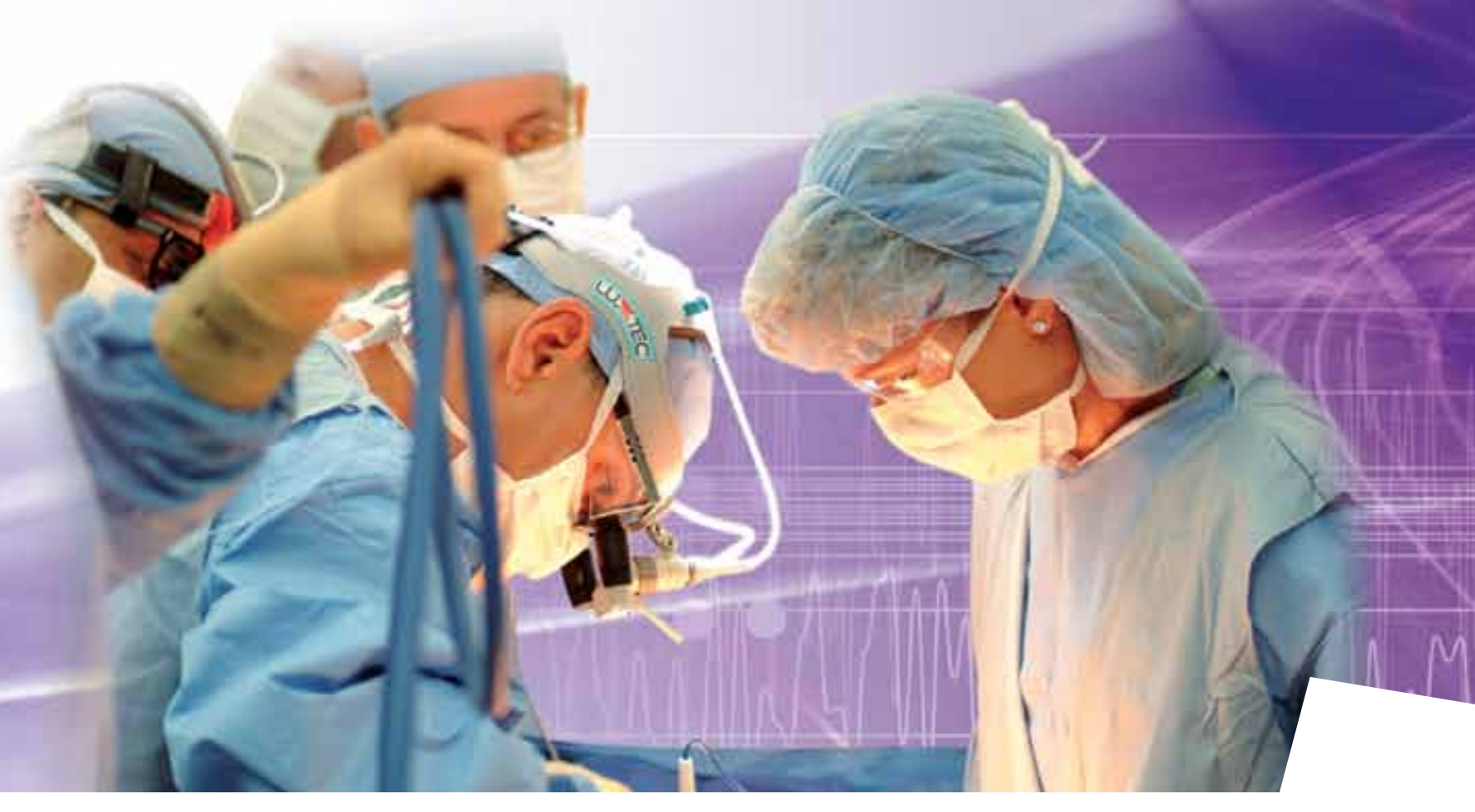

\title{
Bioética e Confidencialidade do Doador Cadáver em Transplantes Renais no Brasil
}

BIOÉTICAY CONFIDENCIALIDAD DEL DONANTE CADÁVER

BIOETHICS AND CONFIDENTIALITY REGARDING CADAVER DONORS FOR KIDNEYTRANSPLANTATION IN BRAZIL

Telma Noleto Rosa*

> Volnei Garrafa**

\section{Fecha de evaluación: Octubre 20 de 2011}




\section{RESUMO}

Objetivo - Analisar a confidencialidade nos transplantes renais com doadores cadáveres. MÉTODOLOGIA - Foram aplicados 60 questionários com participantes escolhidos aleatoriamente, divididos em três grupos: pacientes em lista de espera para transplantes, pacientes transplantados renais e familiares dos doadores. RESULTADOS - No grupo de pacientes em lista de espera, $85 \%$ manifestaram interesse em conhecer a identidade do doador; no grupo de pacientes transplantados, apenas $45 \%$ manifestaram interesse; no grupo de famílias doadoras, 55\% manifestaram vontade de conhecer o receptor. A Central Nacional de Notificação, Captação e Distribuição de Órgãos (CNCDO) foi indicada por $61.7 \%$ dos participantes como responsável pela identificação do doador. CONCLUSÃO - O critério da decisão compartilhada sobre a identificação ou não do doador cadáver, com a intermediação do Estado por

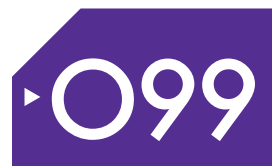
meio das CNCDO, é o mais condizente com a opinião dos sujeitos que responderam à amostra estudada.

\section{Palavras clave}

Bioética; Transplante renal; Doador cadaver; Confidencialidade.

\section{RESUMEN}

Objetivo - Analizar la confidencialidad en los trasplantes renales con donantes cadáveres. Metodología - Se aplicaron 60 cuestionarios con participantes escogidos aleatoriamente, divididos en tres grupos: pacientes en lista de espera para trasplantes; pacientes renales trasplantados; y familiares de los donantes.

Resultados - En el grupo de pacientes en lista de espera, el 85\% manifestó interés en conocer la identidad del donante; en el grupo de pacientes trasplantados, sólo el 45\% manifestó interés; en el grupo de familias donantes, el 55\% manifestó el deseo de conocer el receptor. La Central Nacional de Notificación, Captación y Distribución de Órganos (CNCDO) fue indicada por un $61,7 \%$ de los participantes como responsable por la identificación del donante.

Conclusión - El criterio de decisión compartida sobre la identificación o no del donante cadáver, con la intermediación del Estado a través de las CNCDO, es lo que más se ajusta a la opinión de las personas que respondieron a la muestra estudiada.

Palabras Clave

Bioética, Trasplante Renal, Donante Cadáver, Confidencialidad.

\section{SUMMARY}

Objetivo - To analyze the confidentiality in kidney transplantation from cadaver donors. METHODOLOGY - Questionnaires with 60 participants divided in three groups: patients on waiting lists for transplants; patients who had received a transplant; and members of donors' families. RESULTS - In the first group, $85 \%$ expressed interest in knowing the donor's identity; in the second group, only $45 \%$ expressed interest; and in the group of donor families, $55 \%$ expressed a wish to know who had received the transplant. The National Center for Organ Notification, Collection and Distribution (CNCDO) was indicated by $61.7 \%$ of the participants as the body responsible for donor identification. CONCLUSION - The criterion of shared decisions between the subjects involved, with intermediation by the State through CNCDO, fitted best with the opinions of the sample studied.

\section{Key words}

Bioethics. Kidney transplantation. Cadaver donor. Confidentiality. 


\section{INTRODUÇÃO}

A política brasileira de transplantes está fundamentada em legislação específica (MINISTÉRIO DA SAÚ$D E$, 2007). O conjunto das leis definiu como diretrizes a gratuidade da doação, a beneficência em relação aos receptores, a não maleficência em relação aos doadores vivos e estabeleceu garantias e direitos aos pacientes que necessitam destes procedimentos. Entretanto, questões conflitivas, como a manutenção ou não da confidencialidade com relação à identidade do doador cadáver, ainda não estão contempladas na legislação, bem como as discussões sobre o tema são ainda incipientes.

A não inclusão da confidencialidade da identidade do doador cadáver na legislação de transplantes e nos ciclos de discussões sobre o tema no Brasil, especificamente, corroboram para a existência de critérios técnicos divergentes entre as Centrais de Notificação, Captação e Distribuição de Órgãos (CNCDO) nos diferentes estados do país.

A diversidade de critérios técnicos frente a confidencialidade da identidade do doador propicia o aparecimento de conflitos pessoais, psicológicos, sociais e éticos tanto nos profissionais que mantêm o contato direto com os pacientes e seus familiares, como na população em geral, mesmo porque a legislação brasileira somente autoriza a inscrição de paciente em uma única lista de espera, em qualquer Estado. E essa mesma legislação autoriza, também, a realização de transplante de um órgão advindo de outro Estado e vice-versa, por meio da distribuição de órgãos e tecidos de uma lista única nacional, fatores que favorecem a observação dessa ambigüidade pelos usuários de todo o sistema no país.

A diversidade de posturas das CNCDO promove, intermitentemente, conflitos e questionamentos nas famílias doadoras e receptores sobre o direito ao exercício da autonomia, dentro de pontos de vistas diferentes: o pessoal e o impessoal.

A Declaração Universal sobre Bioética e Direitos Humanos da Unesco reconhece que: "...as decisões sobre questões éticas na medicina, ciências da vida e tecnologias associadas podem ter um impacto sobre os indivíduos, famílias, grupos ou comunidades e sobre a humanidade como um todo" (UNESCO, 2005). Assim, seria imprudente discutir a doação de órgãos e tecidos, assim como os transplantes, apenas na dimensão quantitativa, sem considerar o respeito à qualidade de vida das pessoas, e outros conceitos fundamentais relacionados com a ética, como autonomia, cidadania, direitos humanos e liberdade, dentre outros.

A ética prática (aplicada), que propicia discussões, analisa casos, confronta idéias e argumenta com base na razão a dimensão da ética em saúde pública, pode auxiliar na resultante moral do conjunto de decisões e medidas políticas e sanitárias - individuais e coletivas - que possam proporcionar aumento da cidadania e diminuição da exclusão social (GARRAFA V. A., 1995. p. 05-9).

Portanto, o debate sobre a manutenção ou revelação do sigilo da identidade do doador requer maturidade social. E essa deve ser conquistada por meio do diálogo, da informação e discussão do assunto com segmentos da sociedade e, principalmente, com aqueles que direta ou indiretamente estejam ligados ao processo de doação e transplantes, com vistas a favorecer uma mudança cultural consciente e à implementação de leis que possam, assim, refleti-la.

O objetivo do presente estudo foi analisar, sob o prisma da bioética, a confidencialidade em relação à identidade do doador nos casos de transplantes renais de doadores cadáveres no Brasil. E, identificar a opinião de pacientes renais em lista de espera para transplante, pacientes transplantados e pessoas formalmente responsáveis de famílias doadoras, sobre a confidencialidade em relação à identidade do doador cadáver.

\section{METODOLOGÍA}

Os participantes da amostra utilizada no presente estudo foram selecionados por meio de escolha aleatória simples, nas listagens de pacientes e doadores das Centrais de Notificação, Captação e Distribuição de Órgãos do Estado de Goiás (CNCDO-GO) e do Distrito Federal (CNCDO-DF), no Brasil.

A amostra foi composta por 60 pessoas, de ambos os sexos, idade superior a 18 anos, residentes em Goiânia-GO ou no Distrito Federal. A pesquisa foi previamente aprovada pelo Comitê de Ética em Pesquisa com Seres Humanos da Faculdade de Ciências da Saúde da Universidade de Brasília, devidamente credenciado à Comissão Nacional de Ética em Pesquisa (CONEP) do Ministério da Saúde do Brasil. Após a assinatura do Termo de Consentimento Informado, os participantes responderam a um questionário formatado com 
perguntas abertas e fechadas, dirigidas a três grupos de sujeitos distintos:

Grupo 1 - composto por 20 pacientes em lista de espera para transplante renal: 10 inscritos na lista de espera para transplante na CNCDO-GO e 10 na CNCDO-DF.

Grupo 2 - consistiu de 20 pacientes transplantados renais de doadores cadáveres, com registro da realização do transplante há mais de 6 meses: 10 na CNCDO-GO e outros 10 na CNCDO-DF.

Grupo 3 - formado por 20 familiares responsáveis pela assinatura do Termo de Consentimento de Doação de Órgãos e Tecidos: 10 de Goiás e 10 do DF (Tabela 1).

O critério de exclusão dos participantes dos três grupos foi o laço de parentesco com profissionais da

\begin{tabular}{|c|c|c|}
\hline Variável & $\mathbf{N}$ & $\%$ \\
\hline \multicolumn{3}{|l|}{ Sexo } \\
\hline Masculino & 36 & 60 \\
\hline Feminino & 24 & 40 \\
\hline \multicolumn{3}{|l|}{ Faixa etária: } \\
\hline 18 a 29 anos & 7 & 11,6 \\
\hline 30 a 49 anos & 34 & 56,7 \\
\hline 50 a 59 anos & 13 & 21,7 \\
\hline mais de 60 anos & 6 & 10 \\
\hline \multicolumn{3}{|l|}{ Estado civil: } \\
\hline Casados & 28 & 46,7 \\
\hline Solteiros & 9 & 15 \\
\hline Viúvos & 9 & 15 \\
\hline União estável & 6 & 10 \\
\hline Divorciados & 5 & 8,3 \\
\hline Separados & 3 & 5 \\
\hline \multicolumn{3}{|l|}{ Escolaridade: } \\
\hline Ensino fundamental incompleto & 17 & 28,3 \\
\hline Ensino médio completo & 15 & 25 \\
\hline Ensino fundamental completo & 9 & 15 \\
\hline Ensino superior & 8 & 13,3 \\
\hline Ensino médio incompleto & 6 & 10 \\
\hline Ensino superior incompleto & 4 & 6,7 \\
\hline Pós-graduação & 1 & 1,7 \\
\hline
\end{tabular}

\begin{tabular}{|l|l|l|}
\hline \multicolumn{4}{|l|}{ Atividades profissionais: } & 17 & 28,3 \\
\hline Aposentados & 9 & 15 \\
\hline Atividades comerciais & 8 & 13,3 \\
\hline Autônomos & 8 & 13,3 \\
\hline Do lar & 6 & 10 \\
\hline Fncionários públicos & 6 & 10 \\
\hline Funções administrativas & 2 & 3,3 \\
\hline Área da saúde & 1 & 1,7 \\
\hline Desempregados & 3 & 5 \\
\hline Sem informação & & \\
\hline Renda mensal: & 21 & 35 \\
\hline Até um salário mínimo & 12 & 20 \\
\hline De 1 a 3 salários mínimos & 12 & 20 \\
\hline De 4 a 6 salários mínimos & 9 & 15 \\
\hline De 7 a 10 salários & 4 & 7 \\
\hline Maior que 10 salários mínimos & 2 & 3,3 \\
\hline Sem informação & & \\
\hline
\end{tabular}

CNCDO-GO ou CNCDO-DF, a fim de se evitar qualquer possibilidade de interferência, direta ou indiretamente, no posicionamento dos entrevistados.

Os três questionários utilizados abordaram aproximadamente o mesmo assunto, tendo sido apenas adequados à linguagem específica para cada grupo, conforme descrição a seguir.

Na primeira parte do questionário buscou-se obter os dados pessoais do participante: idade, sexo, cor, estado civil, escolaridade, profissão e/ou ocupação, local de residência, religião, renda e outras especificidades como: tempo em lista de espera, para os entrevistados do Grupo 1; tempo decorrido após a realização do transplante, para os entrevistados do Grupo 2; ou grau de parentesco com o doador, de acordo com a especificidade do Grupo 3.

A segunda parte do questionário abrangeu o tema em seis questões, com tópicos diferenciados de acordo com a especificidade de cada grupo, como já mencionado: 1) O significado da doação de órgãos, com o intuito de conhecer as crenças e valores relacionados ao ato de doar; 2) Se gostaria de ter informação sobre a identidade do doador/receptor; 3) Quem deveria ser responsável pela a informação da identidade do doador/receptor; 
4) Se gostaria de ter a identidade revelada à família doadora/identidade do receptor; 5) Quem deveria ser responsável pela informação da identidade do doador/ receptor; 6) Opinião sobre a possibilidade de conhecer ou não a família doadora/receptor e se isso mudaria alguma coisa em sua vida.

A análise estatística dos dados obtidos pelos questionários foi realizada por meio do Programa Statistical Package for the Social Sciences - SPSS.

\section{RESULTADOS}

Quanto aos dados sócio-demográficos, a amostra da pesquisa teve parcela maior de participantes do sexo masculino (60\%); da faixa etária de 30 a 49 anos $(56.7 \%)$ e de renda familiar até 6 salários mínimos (75\%). A maior parte é de casados (46.7\%); da cor parda $(61.7 \%)$; aposentados (28,3\%) e católicos $(50 \%)$.

Para o significado da doação de órgãos, 30\% escoIheram todas as opções como alternativa (solidariedade, compaixão, generosidade, ser útil aos outros); $25 \%$ indicaram a solidariedade; $16.7 \%$ acrescentaram amor e carinho como outra opção; $11.7 \%$, ser útil aos outros; $8.3 \%$, generosidade; $3.3 \%$ acrescentaram caridade, $3.3 \%$, compaixão e $1.7 \%$, sem informação

Ao considerar o Grupo 1, observou-se que $85 \%$ manifestaram vontade de conhecer a identidade do doador quando transplantado. Destes, $40 \%$ manifestaram vontade, desde que o interesse parta deles próprios; $10 \%$, quando a família do doador manifestar vontade e, $35 \%$, quando, tanto a família doadora quanto o recep-

tor, conjuntamente, manifestarem a mesma vontade. Em contrapartida, 15\% não manifestaram interesse em conhecer a identidade do doador após o transplante

No Grupo 2, 45\% manifestaram vontade de conhecer a identidade do seu doador. Destes, $25 \%$ conheceram a identidade do doador - $15 \%$ manifestaram a própria vontade e $10 \%$ por intermédio da família - e $20 \%$ manifestaram vontade de conhecer, mas mesmo assim não obtiveram a informação da identidade do doador. Os 55\% restantes não manifestaram interesse em conhecer a identidade do doador.

Do Grupo 3, 55\% dos familiares manifestaram vontade de conhecer o(s) receptor (es), mas mesmo assim, apenas $20 \%$ conheceram o(s) receptor(es) e $35 \%$ não obtiveram informação da(s) identidade do(s) receptor(es).
A maioria dos participantes indicou preferência pela CNCDO para assumir a responsabilidade pela identificação do doador - 70\% dos pacientes em lista de espera; $60 \%$ dos pacientes transplantados e $55 \%$ das famílias doadoras.

Dos 20 participantes do Grupo1, 20\% não manifestaram interesse que sua identidade fosse revelada à família doadora; $50 \%$ mostraram-se interessados em revelar sua identidade quando a família tiver interesse; $10 \%$, quando ele próprio, o receptor, tiver interesse; e $20 \%$, quando ele - receptor - e família, conjuntamente, manifestarem interesse.

Dentre os 20 participantes do Grupo 2, 45\% não souberam responder sobre se sua identidade deveria ser revelada à família do doador; $20 \%$ não manifestaram interesse; e 35\% mostraram-se interessados em revelar sua identidade à família. Destes, $25 \%$ somente quando eles próprios autorizarem a identificação; e $10 \%$ quando a família manifestar interesse. Dos familiares questionados sobre quais os motivos que 0 levaram a definir pela doação, $40 \%$ atribuíram como motivação o respeito à vontade do doador; $35 \%$, à solidariedade; $10 \%$, à possibilidade de ser útil aos outros; $5 \%$, como forma de manter o familiar vivo; $5 \%$, à compaixão e $5 \%$ a outros motivos.

\section{DISCUSSÃO}

O estudo constatou que nos três grupos estudados, os sujeitos estão em situação de vulnerabilidade. Desde os pacientes em lista de espera - que vivenciam as mazelas da doença e do tratamento que os excluem de atividades profissionais, sociais e familiares - aos pacientes transplantados, que por um longo período estão com as atenções voltadas para sua recuperação pós-transplante e, consequentemente, para a possibilidade de rejeição do enxerto e falta de acesso à medicação; e até mesmo aos familiares dos doadores de órgãos que, na maioria das vezes, além da situação de estresse em decorrência da morte súbita do doador, deparam-se, posteriormente, com as dificuldades na elaboração do luto.

Para a amostra estudada, a solidariedade, compaixão, generosidade e vontade de ser útil aos outros foram os significados atribuídos à doação de órgãos por $30 \%$ dos participantes. Este simbolismo da doação de órgãos encontra-se presente em diferentes estudos, separadamente, ou em conjunto com outros, confirmando ser a solidariedade uma representação social 
do ato de doar (BENDASSOLI PF. 2000:13). (FONSECA MAA, CARVALHO AM., 2005 (20):85-108).

Em pesquisa na qual foi comparada a tomada de decisão da doação de órgãos de famílias doadoras e não doadoras, constatou-se que a prévia intenção expressa para doação de órgãos pelo doador estava associada ao consentimento de doação da família (RODRIGUE JR, COMELLI DL, HOWARD RJ., 2006 (6):190-8). Também as famílias que optaram em doar tiveram uma maior informação sobre a morte encefálica.

A tomada de decisão das famílias sobre a doação de órgãos, normalmente está envolta com dificuldades emocionais, não somente decorrentes do impacto da noticia da internação súbita e evolução do quadro clinico do paciente (traumatismos, acidente vascular cardíaco, outros) como, também, das dificuldades que permeiam a assistência pública à saúde.

No momento em que os profissionais do sistema de captação oferecem às famílias dos potenciais doadores a oportunidade de se tornarem doadores, os mesmos já tiveram experiências que podem ser decisivas na tomada de decisão, tais como: dificuldade na obtenção de informações fidedignas sobre o paciente; falta de comunicação prévia sobre a abertura do protocolo de diagnóstico de morte encefálica; falta de local físico apropriado para aguardar por notícias; inexistência de contato com a equipe médica; e dificuldades na realização de exames comprobatórios e na transferência de hospitais, quando da necessidade de vaga em leito de Unidade de Terapia Intensiva.

Frente às inúmeras deficiências e pouca credibilidade no sistema público de saúde, e confrontando-se ainda com o medo do desconhecido, torna-se difícil atribuir às famílias a responsabilidade única da negativa para a doação de órgãos. Na verdade, essa responsabilidade deve ser compartilhada com o Estado, responsável pelo precário funcionamento do sistema público e programas de conscientização da população; e, fundamentalmente, com os profissionais da área da saúde, responsáveis também pelo próprio despreparo técnico nas relações interpessoais.

Dois fatores merecem atenção no presente estudo: o primeiro, é que mais da metade dos pacientes transplantados não demonstrou vontade de conhecer a identidade do doador; segundo, ao se manifestar favorável ou desfavoravelmente, a maioria dos participantes da amostra defendeu o direito do exercício da autonomia, requerendo-Ihes o direito de decisão sobre a confidencialidade.
O sigilo profissional sempre foi considerado uma característica moral obrigatória da profissão médica e das profissões na área da saúde. No entanto, no caso da confidencialidade da identidade do doador, o conhecimento técnico do processo de doação e transplante pode não ser suficiente para habilitar os profissionais a uma tomada de decisão mais prudente e justa.

Dentre os 20 participantes do Grupo 2, 45\% não souberam responder sobre se sua identidade deveria ser revelada à família do doador; 20\% não manifestaram interesse; e 35\% mostraram-se interessados em revelar sua identidade à família. 


\section{De acordo com os resultados encontrados por meio do presente estudo, reafirma-se a importância acadê- mica e sócio-política da bioética no auxilio de transfor- mar ações práticas indiscriminadas em ações técnicas responsáveis convergentes aos valores morais prati- cados pela sociedade em cada contexto dado.}

Segundo Ortuzar (ORTUZAR MG., 1998 (7):133158), é obrigação ética a confidencialidade da identidade do doador, como parte de seus interesses, apesar de, frequentemente, ser violada pelos meios de comunicação: o não respeito ao anonimato do doador e receptor pode ocasionar problemas sociológicos no receptor (de identidade pessoal) e culpabilidade pela morte do doador, com perigo de rejeição do órgão.

A CNCDO foi indicada pela maioria dos 60 participantes como a responsável pela possível identificação do doador (61.7\%). Partindo da premissa de que a Constituição Brasileira (Constituição da República Federativa do Brasil. 1988) estabelece que a saúde seja "um direito de todos e um dever do Estado" e que esse deve garantir o "acesso universal e igualitário às ações e serviços de saúde", pode-se inferir que a amostra estudada tem internalizado este conceito de que o Estado é o provedor e, consequentemente, detentor de direitos e deveres. Ao mesmo tempo, os três segmentos - pacientes na lista de espera, transplantados e famílias doadoras se isentam da responsabilidade social da tomada de decisão e reconhecem esse papel como de esfera e competência da CNCDO.

Ressalta-se, ainda, que a possibilidade da quebra da confidencialidade possa ser vista pela população como uma alternativa para o controle social da distribuição dos órgãos: "O controle social, por meio do pluralismo participativo, deverá prevenir o difícil problema de um progresso científico e tecnológico que reduz o cidadão a súdito em vez de emancipá-lo..." (GARRAFA V., 2003).

Sobre quais os motivos que levaram a família a definir pela doação, 40\% atribuíram como motivação o respeito à vontade do doador. Os achados da presente pesquisa confirmam relatos de estudos similares que, em análises multivariáveis, destacaram que o conhecimento das intenções de doação do familiar falecido é fator importante na tomada de decisão favorável à doação de órgãos e tecidos (RODRIGUE JR, COMELLI DL, HOWARD RJ., 2006 (6):190-8) (SIMINOFF LA, GORDON N, HEWLETT J, ARNOLD RM., 2001 (286):71-7) (RADECKI CM, JACCARD J., 1997 (16):183-95). E que os desejos expressados pelos familiares falecidos são usualmente executados pelos membros da família, quando informados. Convém destacar que a efetivação da doação não esteve relacionada a quaisquer formas de incentivo como, por exemplo, a cobertura de despesas de funeral ou outros diferentes benefícios sociais. Embora determinados autores considerem aceitável o uso do benefício funerário à família do doador cadáver (GARRAFA V., PESTANA JOM., 2006:60-75) para cobrir as despesas do enterro, prática utilizada no estado de estado de São Paulo/Brasil, os entrevistados se mostraram veementemente contrários a qualquer "incentivo" financeiro para a doação de órgãos. 
Dentre os pacientes em lista e os transplantados, respectivamente $70 \%$ e $75 \%$ afirmaram que o fato de conhecer a família doadora mudaria positivamente sua vida. Os achados relacionados às famílias doadoras (50\%) mostram que o fato de conhecer os receptores não mudaria sua vida e, exatamente outros $50 \%$ informaram que mudaria.

A manutenção ou não do sigilo da identidade do doador cadáver é um tema que merece pauta nas discussões interdisciplinares e com a comunidade em geral, para que os critérios possam ser estabelecidos de acordo com a moralidade que se configure a partir do próprio contexto sócio-cultural no qual está inserida a sociedade brasileira.

\section{CONCLUÕES}

Na maioria das situações, nos três grupos estudados, os valores individuais se sobrepuseram aos valores coletivos, onde cada um dos três grupos de pessoas estudado chamou a atenção para a necessidade de retomada da autonomia pessoal, uma vez que, enquanto pacientes, esta fica relegada de modo paternalista, muitas vezes, às decisões médicas.

O ponto convergente entre pacientes, famílias e dirigentes foi a presença da referência ao principio da prudência, por meio do respeito e direito mútuo entre as partes envolvidas. Essencialmente, manifesta-se o pluralismo moral observado nas diferenças de opiniões e na congruência das justificativas.

De acordo com os resultados encontrados por meio do presente estudo, reafirma-se a importância acadêmica e sócio-política da bioética no auxilio de transformar ações práticas indiscriminadas em ações técnicas responsáveis convergentes aos valores morais praticados pela sociedade em cada contexto dado.

Observou-se que, uma alternativa para que a confidencialidade da identidade do doador possa ser manejada, é a decisão compartilhada entre os sujeitos envolvidos, com a intermediação do Estado, por meio das CNCDO.

E, para que o Estado possa intermediar de acordo com critérios justos, far-se-á necessário a atuação de três instâncias de Comitês ou Conselhos de Bioética:

Numa primeira instância, após a manifestação do interesse de identificação da identidade dos receptores e famílias doadoras, as partes seriam recebidas por profissionais psicólogos das CNCDO, a fim de que estes pudessem apresentar uma avaliação psicológica a um Comitê Assistencial de Bioética que todo CNCDO deveria ter, o qual daria seu parecer técnico sobre o tema.
Entretanto, os casos que apresentassem dificuldades na avaliação ou tivessem registrados recursos impetrados por qualquer das partes, seriam remetidos a uma segunda instância - o Comitê de Bioética do próprio Sistema Nacional de Transplantes - SNT - podendo, ainda, haver consulta final ao futuro Conselho Nacional de Bioética, ora em tramitação no Congresso Nacional brasileiro por meio do Projeto de Lei 6032/2005 enviado pelo Presidente da República, como terceira e última instância.

\section{REFERENCIAS}

- BENDASSOLI PF. (2000) Do lugar ao não-lugar da doação de órgãos. Psicol. Reflex. Crit. 2000; 13 (1). Disponível em: http://www.scielo.br/scielo. Acesso em: 16 set. 2007. CONSTITUIÇÃO DA REPÚBLICA FEDERATIVA DO BRASIL. (1988) Brasil..

- FONSECA MAA, CARVAlHO AM. (2005) Fragmentos da vida: representações sociais de doação de órgãos e transplantes. Interações. 2005; 20:85-108.

- GARRAFA V. A dimensão da ética em saúde publica. (1995) São Paulo: Faculdade de Saúde Pública USP / Kellogg Foundation. 1995:05-9.

- GARRAFA V. Bioética e manipulação da vida. In: Novaes A (org). (2003) O homem máquina - a ciência manipula o cor po. São Paulo: Companhia das Letras.

- garRAFA V, PESTANA JOM. Bioética do Transplante. In: GARCIA VD, ABBUD-FILHO M, NEUMANN J, PESTANA JOM (orgs). (2006) Transplante de Órgãos e Tecidos. 2.ed. São Paulo: Segmento Farma,. 2006: 60-75.

- MINISTÉRIO DA SAÚDE (2007). Sistema Nacional de Transplantes. Dados estatísticos de. Brasília. Disponível em www.saude.gov.br/transplantes. Acesso em: 03 set. 2007.

- ortuZAR MG. (1998) En pro de la integración regional de la ética y del trasplante de órganos. Cuadernos del Programa Regional de Bioética OPS/OMS 1998, 7:133- 158.

- RADECKI CM, JACCARD J. (1997) Psychological aspects of organ donation a critical review and synthesis of individual and next-of-kin donation decision. Health Psychol 1997; 16:183-95.

- RODRIGUE JR, COMELLI DL, HOWARD RJ. (2006) Organ donation decision: Comparison of donor and nondonor families. American Journal of Transplantation, 2006; 6:190-8.

- SIMINOFF LA, GORDON N, HEWLETT J, ARNOLD RM. (2001) Factors influencing families' consent for donation of solid organs for transplantation. JAMA 2001; 286:71-7.

- UNESCO. (2011) Declaração Universal sobre Bioética e Direitos Humanos. Tradução: Cátedra Unesco de Bioética da Universidade de Brasília, 2005. Disponível em: www.bioetica.catedraunesco.unb.br Acesso em: 10 out. 2011. 